\title{
An Investigation of the Sociality and Behaviour of Captive Polar Bears Housed in Bachelor Groups
}

\section{Alice Cavalleri' ${ }^{1}$, Alexandra Bell ${ }^{1}, K^{\prime m}$ Wilkins $^{2}$, James Brereton ${ }^{3}$, Richard Preziosi $^{1,4}$, and Giovanni Quintavalle Pastorino ${ }^{1,4 *}$}

${ }^{1}$ Manchester Metropolitan University, All Saints, All Saints Building, Manchester M15 6BH, United Kingdom

${ }^{2}$ Yorkshire Wildlife Park, Auckley, Doncaster DN9 3HQ, United Kingdom

${ }^{3}$ University Centre Sparsholt, Westley Lane, Sparsholt, Winchester, SO21 2NF, United

Kingdom

${ }^{4}$ Plymouth University, Drake Circus, Plymouth PL4 8AA, United Kingdom

*Corresponding Author: Giovanni Quintavalle Pastorino, Manchester Metropolitan University, All Saints, All Saints Building, Manchester M15 6BH.

Emial: g_pastorino@hotmail.com

DOI: $10.31080 /$ ASVS.2022.04.0325
Received: February 01, 2022

Published: February 15, 2022

(C) All rights are reserved by Giovanni

Quintavalle Pastorino., et al.

\section{Abstract}

The polar bear (Ursus maritimus) is a popular and easily recognisable species and has a long history of being housed in zoological collections. However, due to concerns regarding space requirements and welfare, many zoos have since removed this species from their collection plans. Polar bears require spacious enclosures with considerable amounts of enrichment and are susceptible to stereotypy if their needs are not met. Yorkshire Wildlife Park, UK, has set up a large enclosure to demonstrate best-practice care of polar bears. Observations of four male captive polar bears were conducted at the collection, to investigate behaviour and sociality between the individuals. Overall, there was limited social interaction between individuals, with very few instances of aggression observed between individuals. Stereotypical behaviour was also rare in all individuals except one. By contrast, affiliative interactions were observed more frequently, particularly between two bears. Overall, polar bears may possess greater behavioural plasticity and flexibility in social behaviour than wild and captive bear literature suggests.

Keywords: Activity Budget; Ursid; Ursus Maritimus; Wildlife Park; Zoo

\section{Introduction}

The polar bear (Ursus maritimus) is a popular, easily recognised ursid, which is currently threatened with extinction due to climate change and habitat loss [1-4]. The polar bear has a long history of being exhibited within zoological collections, with early records dating back to the Tower of London menagerie [2]. However, polar bears remain a challenging species to house in captivity, as the species is prone to stereotypy under conditions that do not meet their welfare needs $[3,5]$. As such, polar bears were gradually phased out of many zoos and wildlife parks in response to animal welfare concerns and changes in regulations [6,7]. The species requires large exhibits to match their natural habitat, whereas historic exhibits traditionally kept polar bears in small exhibits [8].

There is a need, therefore, to develop zoo exhibits that provide sufficient space for polar bears to roam. In an in-situ environment, polar bears can travel hundreds of miles in one-day hunt- ing or searching for a mate [9-11]. In some zoos, polar bears are housed together with conspecifics, with limited room for distancing, whereas research shows that polar bears are a solitary species in their natural habitat with very limited interaction with one another except for during breeding, mothers raising cubs and at congregations $[5,12]$. In light of current research, there are now several exhibits for polar bears that provide considerable space and enrichment opportunities.

In their natural habitat of the Artic, sea ice levels have decreased significantly over the past few decades which is extremely problematic for polar bears because they rely on this space for hunting grounds and breeding [1]. As a result, they are forced inland which causes large congregations to happen, at Hudson Bay for example [12]. These aggregations have created opportunities to observe wild polar bear social networks and behaviours that are rare in a solitary species, particularly when they are not under reproductive stress and when food abundance is high $[10,12]$. 
Solitary bears, particularly males, often show aggressive behaviours towards other bears including young cubs resulting in infanticide when on the sea ice [1] However, research of the sociality at the congregations has found little aggression amongst conspecifics and bears avoiding interactions completely [12]. Bears likely wish to reserve their energy during these long periods of being unable to hunt their usual prey of seals whilst the sea ice is melted [7]. Adult males were seen to remain close to one another, whereas females with cubs stayed away from other bears and move further inland. Sub-adults, both male and female were also found to stay in the same area as each other [12]. A similar social hierarchy was observed in denning females where young mothers would actively avoid older mothers, thus restricting them from feeding opportunities [13]. Hansson and Thomassen [13] found that groups tolerated one another to an extent, however when a solitary female approached the mother bears became alert and aggressive, likely due to solitary bears being a risk to cub mortality [12].

Affiliative interactions at congregations have also been recorded in wild polar bears. Latour [1] observed two adult males taking part in the social play at Hudson Bay when breeding pressures were non-existent and food availability was low. The behaviour was identified as social play because of the restrained nature of the interactions and lack of vocalizations, which are used to differentiate between social and aggressive interactions [14]. The purpose of social play is still not known however research suggests it is advantageous to practice for future agonistic interactions, such as defending a seal kill and competing for females [12].

Previous research has investigated the behaviour of zoo-housed polar bears $[11,15,16]$, with one study conducted at Yorkshire Wildlife Park [8]. Yorkshire Wildlife Park presents an excellent opportunity to observe polar behaviour when animals are housed in bachelor groups and given considerable amounts of space. This study aimed to develop the findings of Quintavalle Pastorino., et al. [8] by further investigating the interactions and behaviour between different male bears.

\section{Materials and Methods}

\section{Study subjects and location}

The study was ethically approved by the Ethics Committee of Manchester Metropolitan University before any observations started. All animals in the study were located in the Project Polar reserve at Yorkshire Wildlife Park. The four individuals in the study were male (Table 1). Victor was the first to arrive at the park in August 2014, with Pixel and Nissan arriving in 2015 and the latest addition, Nobby, arriving in February 2016.

\begin{tabular}{|l|c|c|c|}
\hline Name & Born & $\begin{array}{c}\text { Age during the } \\
\text { study (years) }\end{array}$ & $\begin{array}{c}\text { Relationship to } \\
\text { study animals }\end{array}$ \\
\hline Victor & 18.12 .1998 & 20 & Grandfather of Pixel \\
\hline Nobby & 12.12 .2013 & 5 & None \\
\hline Nissan & 14.12 .2013 & 5 & None \\
\hline Pixel & 16.11 .2012 & 6 & Grandson of Victor \\
\hline
\end{tabular}

Table 1: Species profiles.

The polar bears are maintained in three large outdoor enclosures (Zones 1, 2 and 3) with access to a smaller indoor enclosure space (Zone 4) that contains four off show dens and a small outdoor area containing a saltwater pool along with living trees and tree trunks (Figure 1). The total size of all enclosures is approximately seven and a half acres however there are plans in the future to build another enclosure, which will increase the total size to 10 acres (Figure 1).

The three large enclosure zones consist of an open, grassy area with small hills, lakes and at least one stone cave in each that the bears can enter and climb on top of. Enclosures 1 and 3 each contain a 10-metre deep lake and enclosure 2 contain4-meteretre a deep lake. Enclosure 3 also contains another shallower, 1.5-meterdeep lake. All enclosures are linked by connecting tunnels (including Zone 4), which, when open, allow the bears to roam between all paddocks and be sectioned off from one another when necessary.

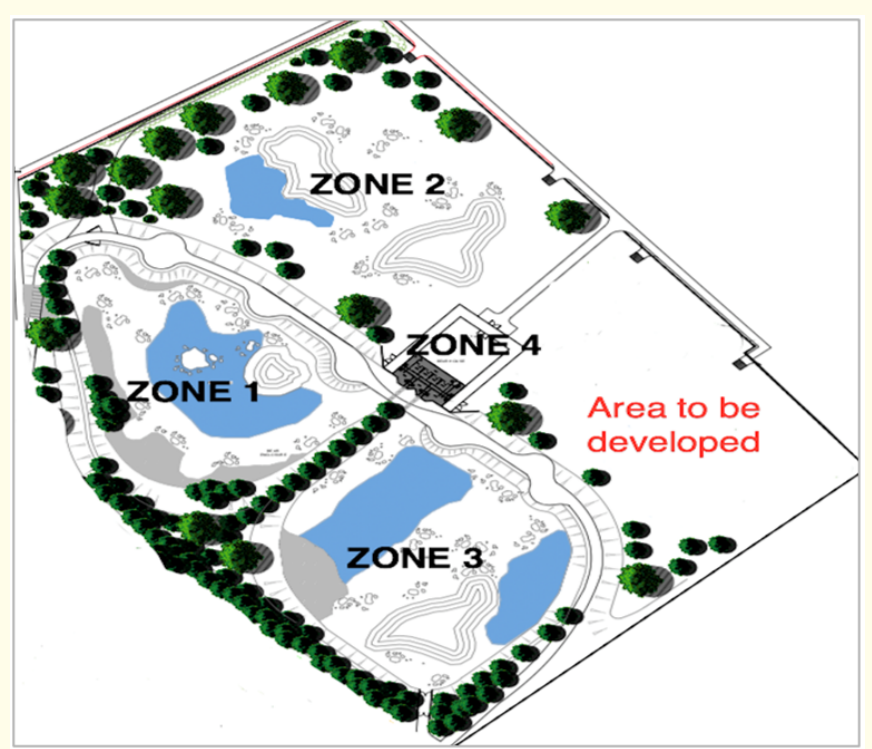

Figure 1: Aerial View of the Zones within Project Polar. 
An aerial view of the enclosures can be viewed in Figure 1.

During the time of the study, it was breeding season and aggressive behaviour was an issue (K Wilkins, YWP carnivore team leader, personal communication, 5th Nov 2021). Because of this YWP control, the bear's access to each other whilst hormone levels are (is) high to reduce agonistic behaviours. Nissan and Pixel were housed separately from Victor and Nobby due to previous aggressive behaviours towards one another. Nobby was given access to Nissan and Pixel on occasion for social interactions but it was time-limited because Nissan has shown aggression towards him in the past. Victor was top of the hierarchy according to YWP staff because of his large size, however, Pixel and Nissan as a pair were capable of challenging him, therefore, were kept separate. This means that this study is limited since all bears did not have access to each other so the frequency of interactions between bears is not accurate, therefore the focus is on the quality of social interactions.

\section{Behavioural observations}

Observations were taken of the four male polar bears from 17 th May to 11th June 2019 over 16 days in total. Videos were captured on a CANON Legria camcorder, each individual was recorded for 15-minute periods twice a day, once in the morning and another in the afternoon. A continuous focal sampling method was used to determine bear behaviour [17]. Videos were captured from the visitor viewing area which meant that each bear was not always visible to visitors or the video camera. An ethogram was created based on previous sociality studies for polar bears [8]. The etho-

\begin{tabular}{|c|c|}
\hline Behaviour category & Description \\
\hline Affiliative behaviour & $\begin{array}{l}\text { Positive/friendly behaviours towards conspecifics such as playing, sniffing, watch- } \\
\text { ing, licking, nuzzling and rubbing. }\end{array}$ \\
\hline Aggression & Aggressive/negative displays towards conspecifics, including biting and chasing. \\
\hline Exploratory behaviour & $\begin{array}{l}\text { Interacting with and scanning the environment. Handling, sniffing, tossing or rub- } \\
\text { bing against objects or parts of the enclosure. }\end{array}$ \\
\hline Foraging & $\begin{array}{c}\text { Bear is actively searching and consuming food. This includes chewing, biting and } \\
\text { licking. }\end{array}$ \\
\hline Grooming & $\begin{array}{l}\text { Natural somatic behaviours such as drinking, urinating, defecating, grooming, } \\
\text { yawning, licking, shaking and scratching. }\end{array}$ \\
\hline Inactive & $\begin{array}{c}\text { Bear is lying (on side, back or stomach), sitting, standing on four paws or upright } \\
\text { on two paws whether on land or bathing in water. }\end{array}$ \\
\hline Locomotion & $\begin{array}{l}\text { Movement of the bear such as walking or running on land, diving into water, swim- } \\
\text { ming in water, climbing on structures/hills, playing/sparring. }\end{array}$ \\
\hline Stereotypy & $\begin{array}{l}\text { Behaviour not exhibited in the wild. Pacing, or walking repeatedly along the same } \\
\text { path or swimming along same stretch of water. }\end{array}$ \\
\hline Out of sight & The bear is not visible to the researcher. \\
\hline
\end{tabular}

Table 2: Categories of behaviours exhibited by the bears during observations [8].

gram contained 43 behaviours which were consolidated into 8 categories (Table 2).

Each video was analysed for behavioural data using Behavioural Observation Research Interactive Software (BORIS) v 7. 10. 5. BORIS is an event logging software for video coding and live observations. This software allows modifiers that are used to add further detail to a recorded behaviour such as Sniff object or conspecific. This gives more context behind a recorded behaviour [18]. After observational data was collected, activity budgets were created using BORIS's time budget function. Out-of-sight behaviours such as 'enters indoors', were used as a correctional factor so that observation results were based on periods where the bears were visible to the camera.

\section{Data analysis}

The results from the observations were uploaded into a Mi- 
crosoft Excel $^{\text {TM }} 2016$ spreadsheet, and then transferred to Minitab version 2.7 for analysis. For association-based information, a sociogram was developed to show the frequency of proximity between individual bears. Proximity was defined as being within one bearlength of another individual, and proximity was defined as being within two bear-lengths. A general activity budget was created first to give a general overview of how the bears spend their time. Then a social time budget was created to represent how much of their time was interacting with their conspecifics. Finally, to represent the relationships within the group a sociogram was made based on each individual's interaction with their conspecifics using the data collected

\section{Results and Discussion}

\section{Behaviour}

An activity budget was created to show the most common behaviours across all footage and every individual (Figure 2). The 'Other' behavioural category was the most observed group, and 'off camera' behaviour was the least commonly observed. Individual activity budgets were also generated to identify how individual bears spent their time throughout the study (Figure 3). Nissan was most frequently observed engaging in 'inactive', behaviour, Nobby spent most time engaged in 'locomotion'. For Pixel, the most common behaviour was 'inactive' and Victor spent most time engaging in 'other' behaviours. A final activity budget was created to show and compare each bear's time performing affiliative interactions only (Figure 4). The results varied between each bear significantly.

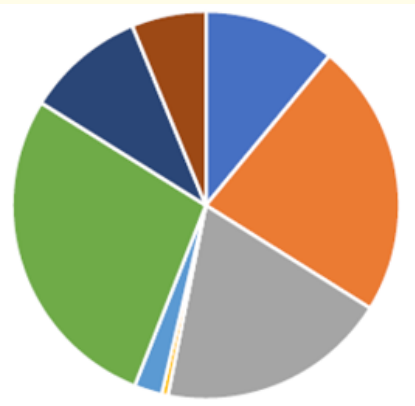

- Foraging = Inactive " Locomotion = Negetive Social "Off Camara "Others - Social - Stereotypical
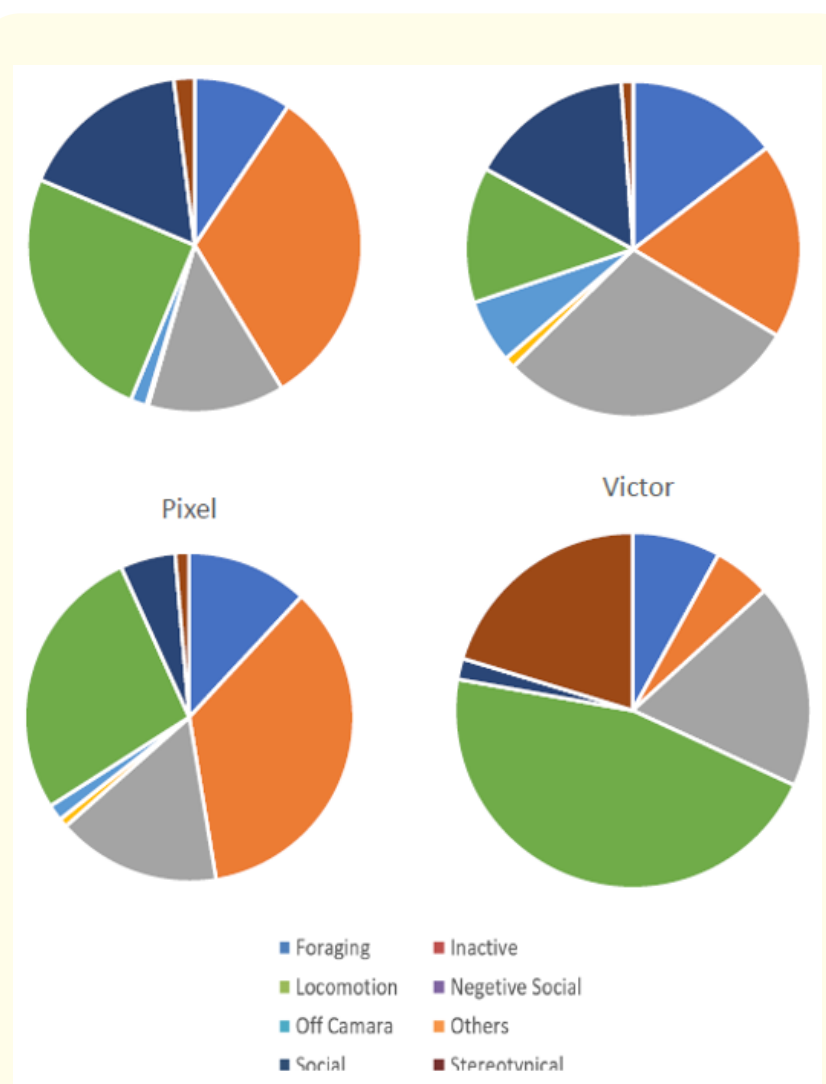

Figure 3: Activity budgets for each bear represented by pie charts.

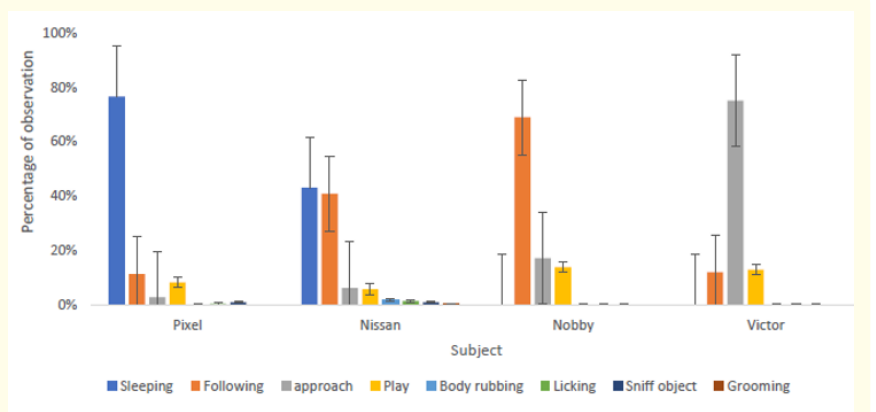

Figure 4: An activity budget of a time budget of affiliative behaviours only for all subjects.

Figure 2: A general time budget for all polar bears. 
Nissan and Pixel were observed performing social behaviour most frequently of all bears observed.

\section{Social interaction}

A sociogram was developed to illustrate the frequency of inter-

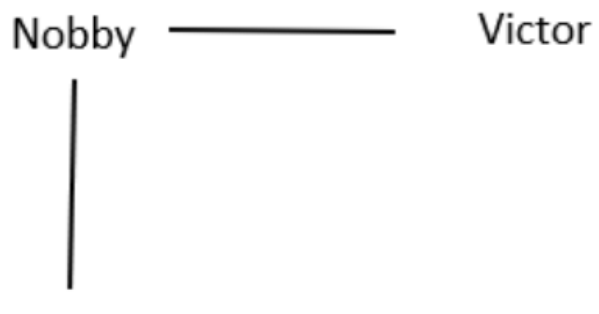

\section{Nissan Pixel}

Figure 5: A sociogram was created of the bears based on their interactions with each other. The thickness of the line indicates the sum of the amount times the bears interacted with one another

actions between the four polar bears in the study (Figure 5). Thicker lines indicate more frequent interactions between individual bears.

\section{Behaviour evaluation}

Overall, the behaviour of bears differed significantly between individuals. Throughout the study, the 'other' behavioural category was most frequently observed. This is likely because this category includes the physical characteristics of each bear such as 'looking around'. The second most common category was inactive. This is particularly interesting because the previous study by Quintavalle Pastorino., et al. [8] using camera traps was limited to seeing mainly locomotive behaviours because of the motion-triggered nature of the cameras. Although some inactive behaviours were recorded, in comparison to this current study, the bears were inactive for a significantly greater proportion of time during observations. It is important to note that both studies were conducted over different time scales, however, using video cameras and focusing on one individual at a time has overcome certain obstacles of using camera traps.
Observations of stereotypical behaviour were low or non-existent in all of the subjects except one. Victor was observed pacing on multiple occasions, which is the most common type of stereotypy in bears $[19,20]$. In the previous study using camera traps Quintavalle Pastorino., et al. [8] study found that stereotypical behaviours were the least observed category. The causation of these infrequent bouts of stereotypy is unclear. Stereotypy may be related to frustrated behaviours, such as limited opportunities for foraging and hunting [21]. On the other hand, stereotypy occurs more frequently in older animals [16], and maybe a behavioural scar, in that once formed, the stereotypy rarely disappears entirely $[3,5]$. It is therefore interesting that the stereotypy occurred in the oldest animal, Victor, and therefore the stereotypy may also be related to previous housing and age rather than current housing provisions.

Stereotypy may also have been influenced by season. At the time of this study, it was breeding season, during this time the four males' bears are separated to prevent aggression towards one another (Quintavalle Pastorino and Cavalleri, unpublished data). Although it is not certain, the separation between the other bears may have been stressful for Victor resulting in pacing and might mean social interactions can reduce these types of behaviours as it has done in other species such as tigers (Panthera tigris) [20,22].

\section{Sociality}

Both antagonistic and affiliative behaviours were observed during the study, however affiliative interactions occurred more often, particularly between Nissan and Pixel. Victor and Nobby also interacted positively but in comparison to Nissan and Pixel there was significantly less interaction. Nissan was regularly observed following Pixel around the enclosure and the pair were regularly observed sleeping alongside one another. This type of relationship has not been previously reported in published literature. The relationship is particularly unusual as it is displayed between two adults, unrelated male bears.

Anecdotal observations at Cochrane Polar bear Habitat of an adult male polar bear displaying guarding behaviour towards another male have been noted, but not published (G Quintavalle Pastorino, personal observation). However, in this instance the bear being guarded showed no affiliative interaction with the bear guarding it. A similar interaction has been observed between Asiatic black bears (Ursus thibetanus) where two females were protec- 
tive towards each other and remained close [23].

The lack of aggressive behaviour in the polar bears may be comparable to congregations at Hudson Bay, where large numbers of bears congregate due to food availability. In the enclosure at Yorkshire Wildlife Park, food is regularly available and there are no females to compete for in their enclosure, it reduces competition, allowing them to form companionships or behave affiliative towards one another. As previously mentioned, male polar bears have been observed playing at the congregations or remaining close to one another with very little aggression in comparison to when they on solitary on the sea ice [12]. However, when sea ice reforms there are no reports to determine whether this behaviour continues. Overall, polar bears may have greater social and behavioural plasticity than has been previously reported in either captive or zoo literature.

Negative social interactions, which include aggression, antagonistic, and avoidance behaviours were rarely seen throughout the observations. It is important to note that this study took place during breeding season when hormone levels were high in which YWP take precautions by separating bears that have shown aggressive behaviour towards each other in the past, therefore the quantity of interactions is not as accurate as the camera trap study where bears had access to one another at all times. Even so, there was still little aggression found using camera traps which is likely because the enclosure at Yorkshire Wildlife Park is spacious and naturalistic, therefore bears were able to avoid each other if they wanted to avoid negative interactions as they would in the wild [8]. Similar results were shown in two female captive bears where they actively moved away from one another when they were nearby which meant aggressive interactions were recorded rarely [10]. From the result in this study and others it can be concluded that bears do have a level of behavioural plasticity to adapt to their surroundings whether it is at congregations or in captivity.

\section{Limitations and Future Directions}

Since the observations were taken in 2019, Nissan and Pixel have moved to De Cerza Zoo together to reduce stress in their new environment. The pair have been moved in the hopes they will breed with two females at the zoo. Further observations of the pair at a different zoo would determine whether affiliative interactions continue between the pair when females are available.

This study was undertaken during a relatively brief period and as such, future studies should investigate polar bear behaviour over a much greater length of time, ideally covering all seasons. This would allow a more holistic overview of behaviour to be investigated. Unfortunately, it was beyond the scope of this study to investigate all time periods and seasons, though future studies could also investigate the behaviour of bears during, for example, the night.

Polar bears should no longer be classed as a completely solitary species when in captivity. It is clear from the literature and the results of both studies demonstrate that they have a complex social capability and housing them socially can be beneficial if the individuals are compatible with one another [20,22]. Or they should have the choice to avoid conspecifics by providing them with spacious exhibits. Further research into whether particular animal temperaments influence affiliative interactions between individuals would be valuable. According to Yorkshire Wildlife staff, Nissan was the preferred bear by all other conspecifics.

Enclosure use data was not obtained during this study, therefore a suggestion for further research would be to collect data on enclosure use and to see if there is a correlation between behaviours and where they are performed. The studies could help to identify whether the bears were choosing to spend time in close proximity, or whether individuals had a specific set of enclosure zones each.

\section{Conclusion}

This study has provided an insight into the interactions in a bachelor group of four male polar bears, which showed very few incidences of aggression and frequent affiliative interactions. Limitations to where bears could go may have reduced the number of interactions observed however when compared with an earlier camera trap study it is clear polar bears are able to co-exist with one another as long as there is sufficient space to meet their needs. This study shows evidence of affiliative interactions between bears, however, to understand why these occur requires further research into captive polar bear behaviour is recommended. It is reasonable to conclude that Yorkshire Wildlife Park meets the needs of these four males as only one bear was frequently observed performing 
stereotypical behaviour which may in part be related to the bear's separation. There are still limited data on polar bear sociality in captivity and the wild, as they are an endangered species it is essential to study further in order to better understand population dynamics, behaviour and social plasticity for future conservation efforts.

\section{Acknowledgements}

The authors would like to thank the keepers at Yorkshire Wild-

\section{Bibliography}

1. Amstrup S., et al. "Recent observations of intraspecific predation and cannibalism among polar bears in the southern Beaufort Sea". Polar Biology 29.11 (2006): 997-1002.

2. Carlstead K., et al. "Environmental enrichment for zoo bears". Zoo Biology 10.1 (1991): 3-16.

3. Clubb R and Mason GJ. "Natural behavioural biology as a risk factor in carnivore welfare: How analysing species differences could help zoos improve enclosures". Applied Animal Behaviour Science 102.3 (2007): 303-328.

4. Courchamp F., et al. "The paradoxical extinction of the most charismatic animals". PLoS Biology 16 (2018): e2003997.

5. Kroshko J., et al. "Stereotypic route tracing in captive Carnivora is predicted by species-typical home range sizes and hunting styles". Animal Behaviour 117 (2016): 197-209.

6. Kelly KR., et al. "Individual effects of seasonal changes, visitor density, and concurrent bear behavior on stereotypical behaviors in captive polar bears (Ursus maritimus)". Journal of Applied Animal Welfare Science 18.1 (2015): 17-31.

7. Dyck MG and Baydack RK. "Vigilance behaviour of polar bears (Ursus maritimus) in the context of wildlife-viewing activities at Churchill, Manitoba, Canada". Biological Conservation 116.3 (2004): 343-350.

8. Quintavalle Pastorino G., et al. "The Challenges of using Camera Traps to Investigate Zoo-Housed Polar Bear (Ursus maritimus) Nocturnal Behaviour". Journal of Veterinary Medicine and Animal Sciences 4.1 (2021): 1-9.

9. Towns L., et al. "Spatial and temporal patterns of problem polar bears in Churchill, Manitoba". Polar Biology 32.10 (2009): 1529-1537.
10. Renner MJ and Kelly AL. "Behavioral decisions for managing social distance and aggression in captive polar bears (Ursus maritimus)". Journal of Applied Animal Welfare Science 9.3 (2006): 233-239.

11. Ross SR. "Issues of choice and control in the behaviour of a pair of captive polar bears (Ursus maritimus)". Behavioural Processes 73.1 (2006): 117-120.

12. Latour PB. "Spatial relationships and behavior of polar bears (Ursus maritimus Phipps) concentrated on land during the icefree season of Hudson Bay". Canadian Journal of Zoology, 59.9 (1981): 1763-1774.

13. Hansson R and Thomassen J. "Behavior of Polar Bears with Cubs in the Denning Area". Bears: Their Biology and Management 5 (1983): 246.

14. Wemmer C., et al. "An analysis of the chuffing vocalization in the polar bear (Ursus maritimus)". Journal of Zoology 180.3 (1976): 425-439.

15. Miller LJ., et al. "The impact of in-person and video-recorded animal experiences on zoo visitors' cognition, affect, empathic concern, and conservation intent". Zoo Biology 39.6 (2020): 367-373.

16. Shepherdson D., et al. "Individual and environmental factors associated with stereotypic behavior and fecal glucocorticoid metabolite levels in zoo housed polar bears". Applied Animal Behaviour Science 147.3 (2013): 268-277.

17. Shora JA., et al. "Should zoo foods be coati chopped". Journal of Zoo and Aquarium Research 6.1 (2018): 22-25.

18. Friard $O$ and Gamba M. "BORIS: a free, versatile open-source event-logging software for video/audio coding and live observations". Methods in Ecology and Evolution 7.11 (2016): 13251330.

19. Montaudouin S and Pape G. "Comparison of the behaviour of European brown bears (Ursus arctos arctos) in six different parks, with particular attention to stereotypies". Behavioural Processes 67.2 (2004): 235-244.

20. Quintavalle Pastorino G., et al. "Personality and Sociality in Captive Tigers (Panthera tigris)". Annual Research and Review in Biology (2017): 1-17.

21. Ovsyanikov NG. "Behaviour of polar bear in coastal congregations”. Zoological Journal 84 (2005): 94-103. 
22. Galardi EG., et al. "An investigation into the Behavior, Sociality and Enclosure Use of Group-Housed Lions and Tigers". Journal of Veterinary Medicine and Animal Sciences 4.1. (2021): 1-9.

23. Ottewell L. "Factors affecting the quantity of social interactions and aggression in captive group housed Asiatic black bears (Ursus thibetanus)". University of Plymouth, United Kingdom (2016).

\section{Assets from publication with us}

- Prompt Acknowledgement after receiving the article

- Thorough Double blinded peer review

- Rapid Publication

- Issue of Publication Certificate

- High visibility of your Published work

Website: www.actascientific.com/

Submit Article: www.actascientific.com/submission.php

Email us: editor@actascientific.com

Contact us: +919182824667 